\title{
Performance Comparison of Various Coding \& Detection Schemes in OCDMA System
}

\author{
Jeffrey Simon $V^{1}$, Dhanya $S^{2}$ \\ ${ }^{1}$ Mahatma Gandhi University, Federal Institute of Science \& Technology, Angamali, Ernakulum, India \\ ${ }^{2}$ Mahatma Gandhi University, Federal Institute of Science \& Technology, Angamali, Ernakulum, India
}

\begin{abstract}
In this paper we evaluate efficiency of a hybrid optical CDMA system on various coding \& detection scheme. OCDMA system based on sub carrier multiplexed (SCM) \& spectral amplitude coding (SAC) is compared using different coding techniques such as Hadamard codes, Double Weighted Codes (DWC) and Enhanced Double Weighted Codes (EDWC) with different detection techniques including complementary, NAND, AND, and XOR. The hybrid system that uses SCM and SAC which improves the data rate in channel as well as mitigates the problem of multiple access interference to a large extend. Upon comparison of different coding schemes like Hadamard codes, DWC \& EDWC; EDWC can support maximum users with high SNR and good quality of service for a considerable range of fiber length. Evaluating different detection schemes, AND and XOR detection are equally efficient. So the proposed scheme focus on a SAC-SCM OCDMA system using EDWC with the help of AND \& XOR detection technique which improves the performance and efficiency of optical CDMA system which can essentially enhance future requirements.
\end{abstract}

Keywords: SAC-SCM-OCDMA system, Enhanced Double Weight Codes (EDWC), XOR detection technique, Multiple Access Interference (MAI)

\section{Introduction}

There are only $25 \%$ CDMA users altogether in world even though CDMA is better in many aspects when compared to GSM system. Many of the problems existing in CDMA system can be overcome using optical CDMA or OCDMA [1]. It can offer high data rate, confidentiality, compatibility with variable bit rate, scalability etc. Traffic by active users can also be effectively managed by OCDMA system. Even though OCDMA is highly efficient, we can still improve the system by using subcarrier multiplexing and spectral amplitude coding. Subcarrier multiplexing enhances the data rate while spectral amplitude coding helps improving spectral efficiency of the system hybrid scheme helps to get advantage of both system simultaneously [2]. Along with this system we will use efficient coding schemes like Hadamard codes, double weighted codes and modified double weight codes [4]. Upon comparing these schemes; enhanced double weight code (EDWC) has got maximum benefits such as maximum number of users, high SNR, minimum interference, maximum scalability. DWC are good in SNR and better than EDWC but lacks the property of supporting maximum users. So here we mainly focus on EDWC coding schemes.

Different detection schemes can be used for OCDMA scheme like complementary AND [3] \& NAND. All the schemes are good for removing multiple access interference but AND scheme proves to be the best. A new detection scheme XOR is implemented which is equally good when compared with AND detection scheme. Performance level of XOR detection technique is not exactly same as AND detection technique, but its closer to that of AND detection. Detection schemes are implemented utilizing correlation.

\section{Code Designs for OCDMA}

We can use different coding schemes for OCDMA such as Hadamard codes, Double Weight Codes (DWC) and Enhanced Double Weight Codes (EDWC). EDWC is better than other methods as it can support maximum number of users, minimum hardware and high SNR.

\subsection{Hadamard codes}

Hadamard code is a matrix form that has an $\mathrm{n} \times \mathrm{n}$ elements. Hadamard codes can be iterated so that it can be extended as per required number of users. It is a code that uses $1 \mathrm{~s}$ and $-1 \mathrm{~s}$ alone; but it is not necessary to use 1s and -1s instead it can be $1 \mathrm{~s}$ and $0 \mathrm{~s}$, or colors like red and green. The $1^{\text {st }}$ raw and $1^{\text {st }}$ coloumn has $n$ number of $1 \mathrm{~s}$; while all the other rows and columns has $n / 2$ number of $1 \mathrm{~s}$ and $0 \mathrm{~s}$. Hadamard matrices will look like as in figure 1

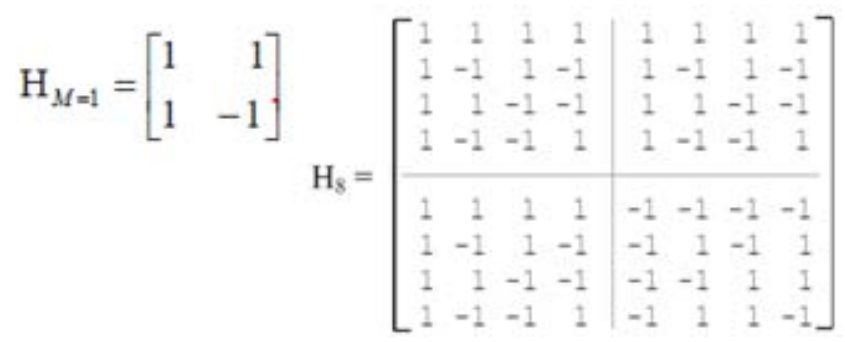

Figure 1: Hadamard codes

\subsection{Double Weighted Codes (DWC)}

Double weight codes contain only two $1 \mathrm{~s}$ in any row; that is why it is named as double weight codes. The main intentions of using such codes are to reduce the number of $1 \mathrm{~s}$ in code and thereby reducing the hardware complexity in designing the system. Even if we iterate the code it still has only two $1 \mathrm{~s}$ in each row, which shows the stability of the systems.

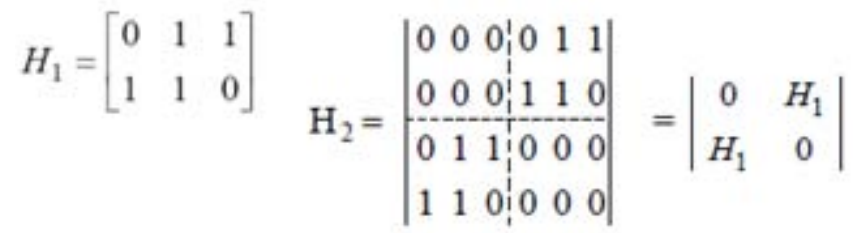

Figure 2: Double Weight Codes

\section{Volume 4 Issue 12, December 2015}




\section{International Journal of Science and Research (IJSR) \\ ISSN (Online): 2319-7064}

Index Copernicus Value (2013): 6.14 | Impact Factor (2014): 5.611

Above shown figure 2 is the way we construct double weighted codes. We can perform iteration in the scheme for supporting maximum number of users.

\subsection{Enhanced Double Weighted Codes (EDWC)}

Enhanced double weighted codes are formed using same principle of double weighted codes. Difference comes only in the weight and way they arranged in the form of matrix. Each row contains $31 \mathrm{~s}$ and upon each iteration too the weight remains same, i.e. code length increases, codes differs but weight remains same.

$$
\begin{gathered}
H_{o}=\left|\begin{array}{lll|ll|ll}
0 & 0 & 1 & 1 & 0 & 1 \\
0 & 1 & 0 & 0 & 1 & 1 \\
1 & 1 & 0 & 1 & 0 & 0
\end{array}\right| \\
H_{1}=\left|\begin{array}{llllll|llllll}
0 & 0 & 0 & 0 & 0 & 0 & 0 & 0 & 1 & 1 & 0 & 1 \\
0 & 0 & 0 & 0 & 0 & 0 & 0 & 1 & 0 & 0 & 1 & 1 \\
0 & 0 & 0 & 0 & 0 & 0 & 1 & 1 & 0 & 1 & 0 & 0 \\
\hline 0 & 0 & 1 & 1 & 0 & 1 & 0 & 0 & 0 & 0 & 0 & 0 \\
0 & 1 & 0 & 0 & 1 & 1 & 0 & 0 & 0 & 0 & 0 & 0 \\
1 & 1 & 0 & 1 & 0 & 0 & 0 & 0 & 0 & 0 & 0 & 0
\end{array}\right|=\left|\begin{array}{cc}
0 & H_{o} \\
H_{o} & 0
\end{array}\right|
\end{gathered}
$$

Figure 3: Enhanced Double Weight Codes

\section{Detection Techniques}

Different detection techniques are employed to evaluate the performance level. Complementary, AND, NAND, XOR are the detection techniques used here.

\subsection{Complementary Detection Technique}

In complementary detection technique, data is made to pass through a code initially and then it is fed to a splitter. At receiver side, we will again use the splitter to pass the same data through different codes of which the first one is same code as used at transmitter side while the second one is the complement of $1^{\text {st }}$ code. Then we will perform subtraction and if we get a zero means it shows that no error encountered, else error exists. Complementary detection technique is the least effective scheme when compared to all other schemes evaluated over here.

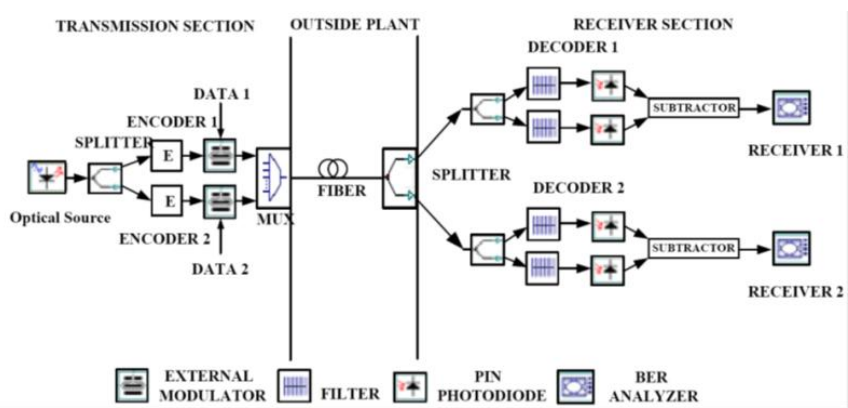

Figure 4: complementary detection technique

Complementary technique needs much heavy hardware than any other detection schemes. Additional hardware will produce more and more noise and hence because of this, interference level is heavy.

\subsection{NAND Detection Technique}

In NAND detection technique, what varies is that, at receiver side we will again use the splitter to pass the same data through different codes of which the first one is same code as used at transmitter side while the second one is the NANDed output of 1 st code\& second user code. Then we will perform subtraction and if we get a zero means it shows that no error encountered, else error exists.

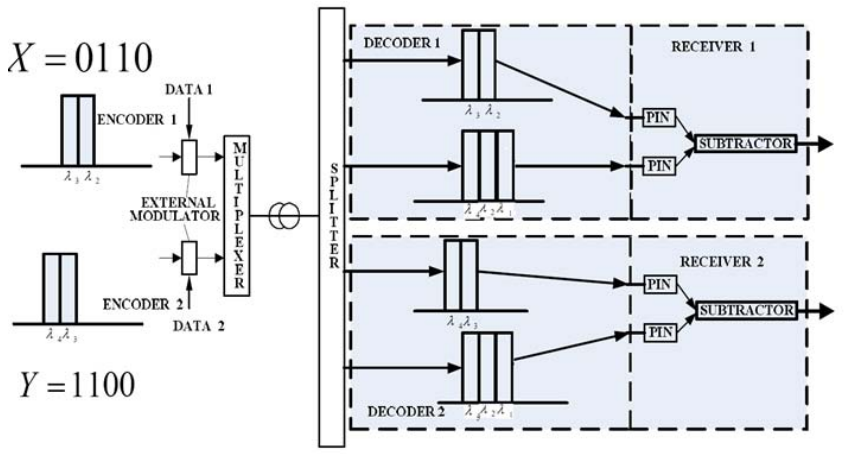

Figure 5: NAND detection technique

NAND detection when compared to complementary detection scheme proves to be better as it requires minimum hardware.

\subsection{AND Detection Technique}

In AND detection technique, at receiver side we will again use the splitter to pass the same data through different codes of which the first one is same code as used at transmitter side while the second one is the ANDed output of 1 st code \& second user code. Then we will perform subtraction and if we get a zero means it shows that no error encountered, else error exists. AND detection technique proves to be most efficient of all schemes. It is equally efficient with XOR detection technique. XOR detection technique is newly implemented in this paper. AND detection uses minimum hardware and it is also capable of supporting maximum users; this is not also because of coding technique, but also because of detection scheme preferred to be used.

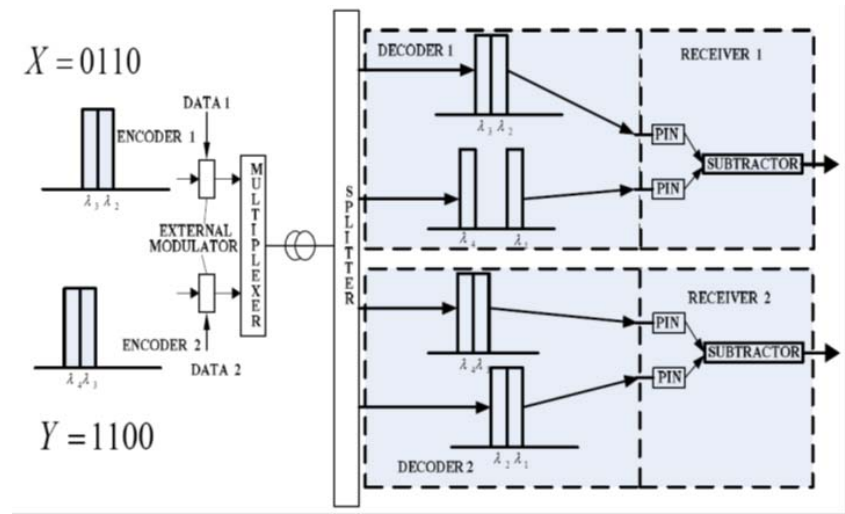

Figure 6: AND detection technique 


\section{International Journal of Science and Research (IJSR) \\ ISSN (Online): 2319-7064 \\ Index Copernicus Value (2013): 6.14 | Impact Factor (2014): 5.611}

In this paper we will evaluate and compare different coding schemes along with different detection techniques.

\subsection{XOR Detection Technique}

In XOR detection technique, at receiver side we will again use the splitter to pass the same data through different codes of which the 1 st one is same code as used at transmitter side while the second one is the XORed output of first code \& second user code. Then we will perform subtraction and if we get a zero means it shows that no error encountered, else error exists.

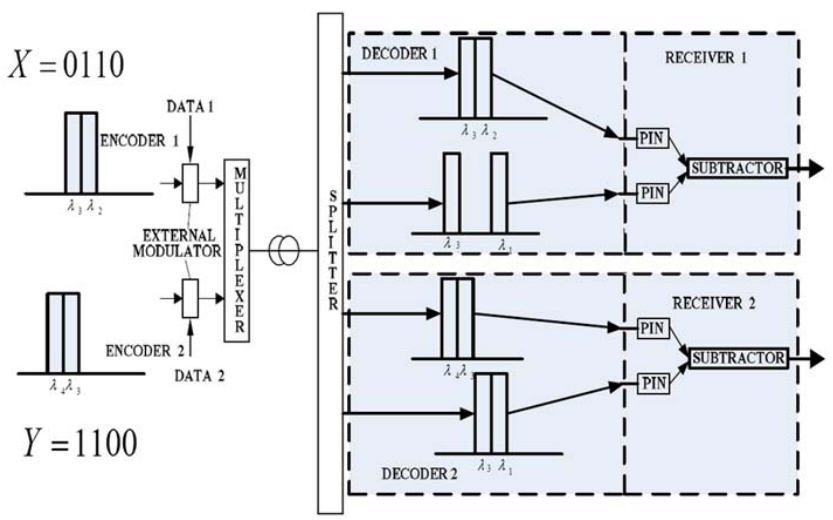

Figure 7 : XOR detection technique

XOR technique is also equally efficient as AND detection technique.

\section{Proposed Model}

The model used here is a hybrid scheme that makes OCDMA efficient enough for the model proposed. It uses both subcarrier multiplexing and spectral amplitude modulation. An optical source set at $1550 \mathrm{~nm}$ is used here, it is a white light source which is fed to a Mach zehnder modulator with extinction ratio $30 \mathrm{db}$. A pseudo random bit sequence generator with $5 \mathrm{mbps}$ data rate is placed which in turn passed to a NRZ pulse generator for making the signal in pulse form. This input is given to mach zehnder modulator. Similarly we will perform this for $\mathrm{N}$ users and will be multiplexed to a fiber then the code is formed using fiber bragg grating (FBG). we use all the 3 coding schemes; Hadamard, DWC, EDWC.code generation is done by varying the wavelength supported by the FBG. It has 3 ports; 1 for input, 2nd one for transmission of wavelength supported and 3rd one for reflected wavelength. The multiplexed data is made to pass through an optical fiber with attenuation factor $0.2 \mathrm{db} / \mathrm{km}$. Fiber length is varied at 10,20,30,40 kms to evaluate the performance. At receiver side we use a power splitter to split up the data and 1st branch is again made to pass through the same user1 code and the 2nd branch is made to pass through a code which is resultant of user1 code operated with user2 code; upon arithmetic subtraction we are supposed to get a zero value. Any change in above condition shows the presence of interference and noise. Note that all the users are made to operate through same optical fiber; code is the only factor that differs between users within the system. Then the subtracted output is fed to a low pass filter and fed to a BER analyzer which can be used to evaluate the performance of the system with the help of BER patterns, graphs and eye diagrams.

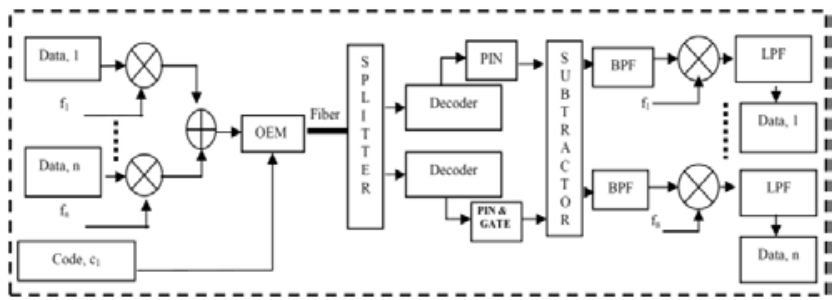

Figure 8: Proposed Model

3 coding schemes are used here Hadamard, double weighted code, enhanced double weight codes. We will compare all the three coding schemes used for OCDMA model. Here DWC and EDWC scheme is best because it can offer less hardware complexity when compared to all other schemes currently available. Figure 5 shows the proposed model.

\section{Experimental Results}

In this paper we evaluated 11 models Hadamard complementary, NAND, AND models, DW-complementary, NAND, AND, XOR models, EDW-complementary, NAND, AND, XOR models. Upon comparison of different coding schemes we will come to the conclusion that the EDWC is the best one.

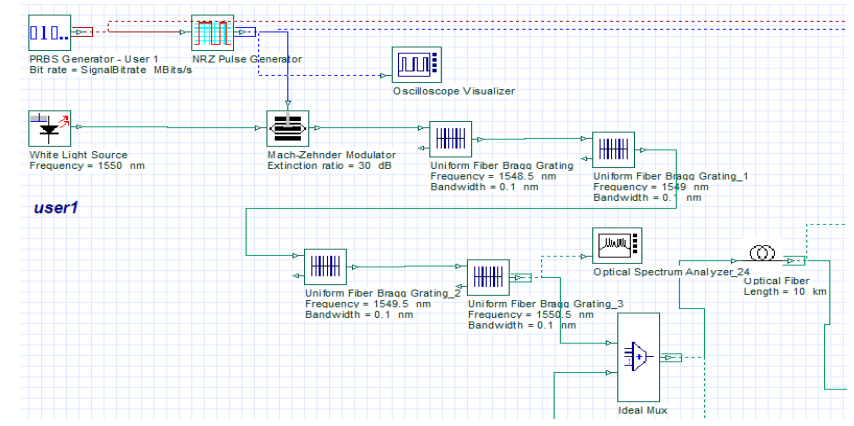

Figure 9: Transmitter side layout for EDWC-AND method

In figure 9 implementation of OCDMA scheme is shown with the help of fiber bragg grating.

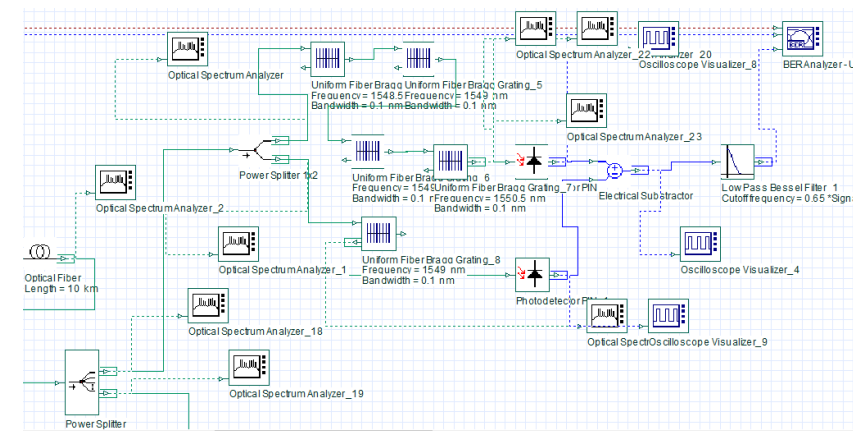

Figure 10: receiver side layout for EDWC-AND method 


\section{International Journal of Science and Research (IJSR) \\ ISSN (Online): 2319-7064}

Index Copernicus Value (2013): 6.14 | Impact Factor (2014): 5.611

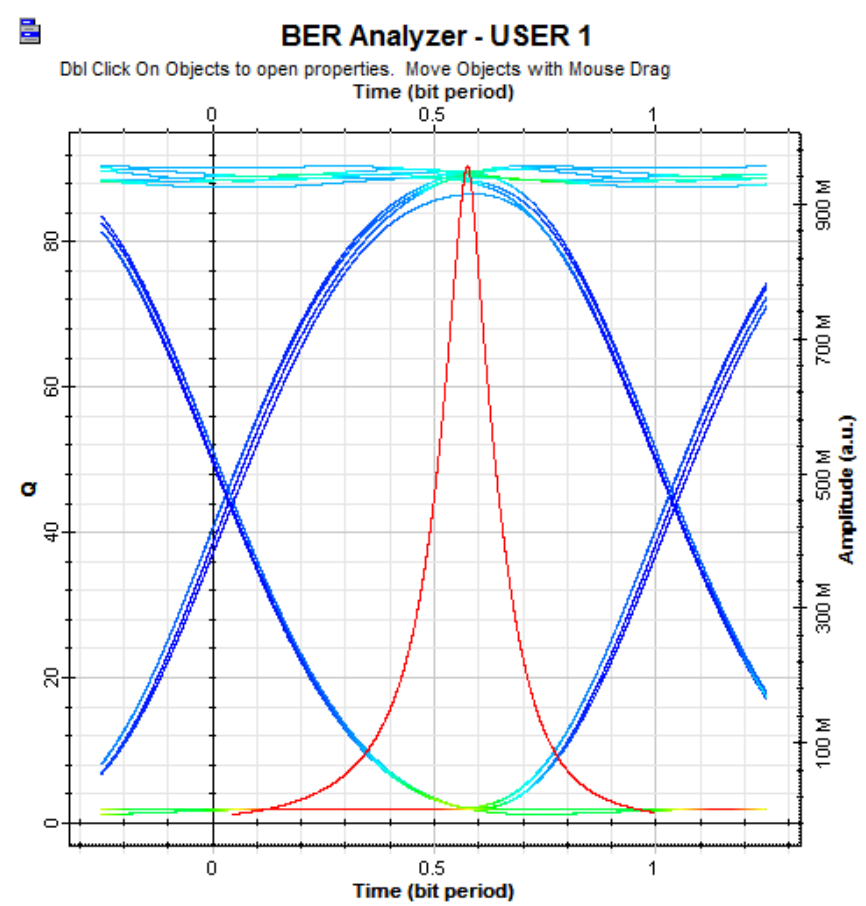

Figure 11: Q-factor \& eye diagram of EDWC-AND method (user 1)

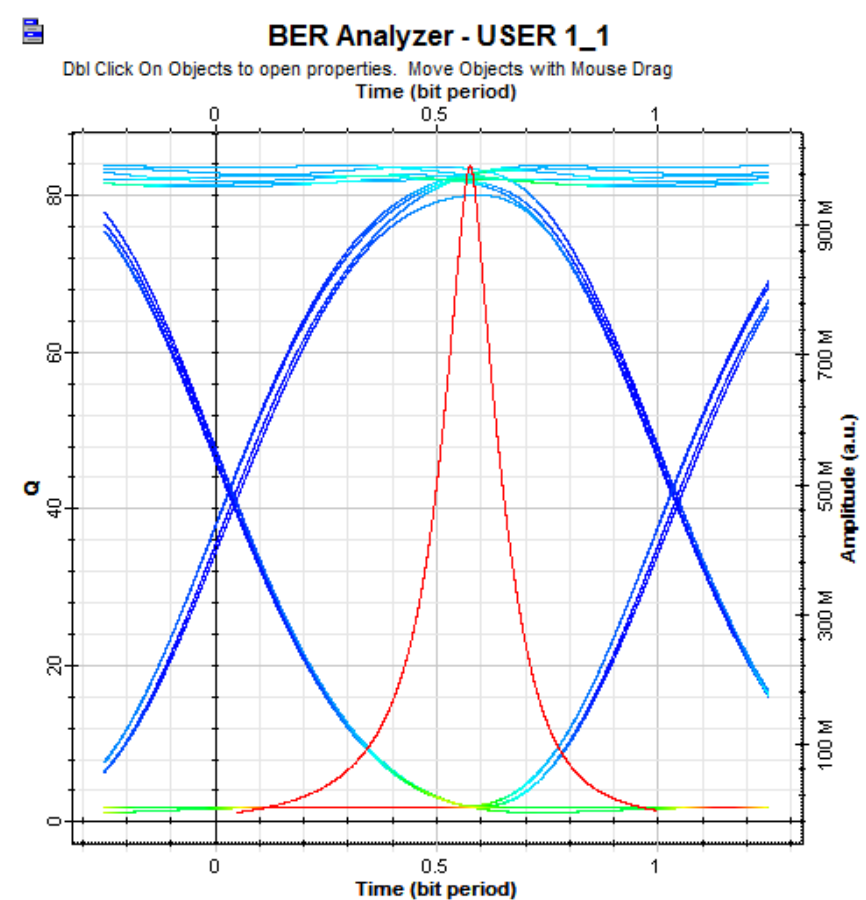

Figure 12: Q-factor \& eye diagram of EDWC-AND method (user 2)

EDWC - AND method is the best one, we can see that eye is opened perfectly, which shows that it is the best one with least interference. The curve with red line depicts the Q-factor value of the model developed. Signal to noise ratio value reflects in Q-factor value of the graph.

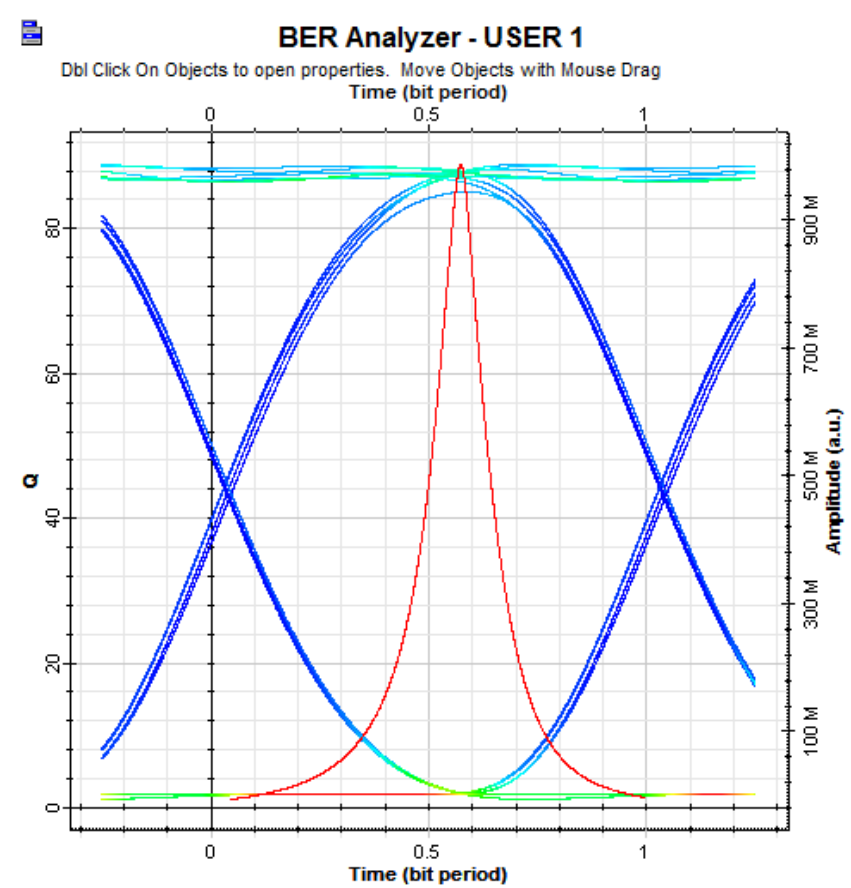

Figure 13: Q-factor \& eye diagram of EDWC-AND method (user 1)

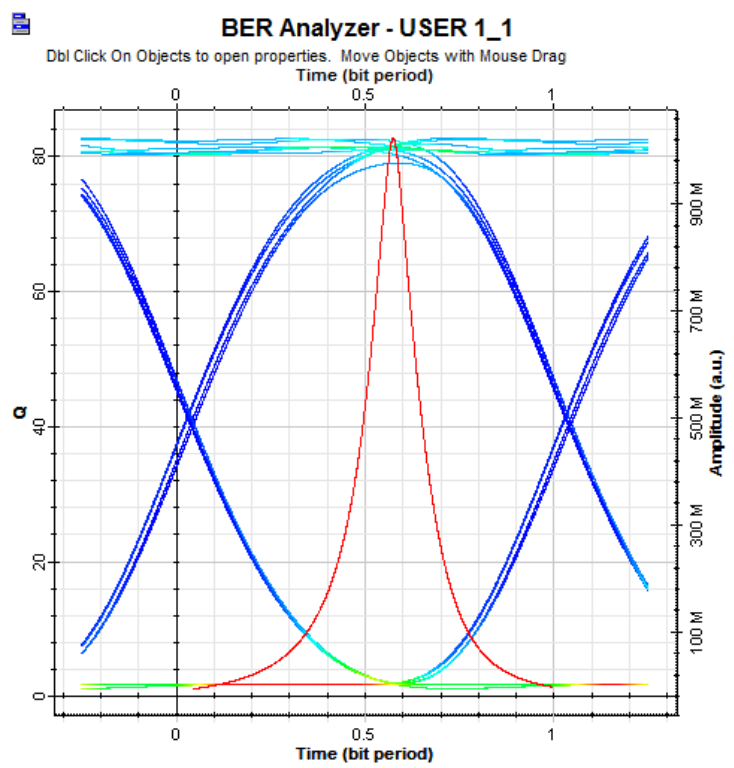

Figure 13: Q-factor \& eye diagram of EDWC-AND method (user 2)

EDWC-XOR method is also equally efficient as EDWCAND method, it too requires minimum hardware and also produce less amount of extra noise, which in turn helps to maintain the quality of Q-factor. From the above graphs it is very clear that system has got better efficiency when compared to all models. Performance of all evaluated models on varying fiber lengths are given below.

\begin{tabular}{|c|c|c|c|}
\hline $\begin{array}{c}\text { FIBER } \\
\text { LENGTH }\end{array}$ & $\begin{array}{c}\text { MAX } \\
\text { Q-FACTOR }\end{array}$ & MIN BER & $\begin{array}{c}\text { DECISION } \\
\text { INSTANT }\end{array}$ \\
\hline $10 \mathrm{KM}$ & 4.5868 & $1.299 \mathrm{e}-006$ & 0.52 \\
\hline $20 \mathrm{KM}$ & 4.8325 & $3.840 \mathrm{e}-007$ & 0.51 \\
\hline $30 \mathrm{KM}$ & 5.0965 & $1.015 \mathrm{e}-007$ & 0.54 \\
\hline $40 \mathrm{KM}$ & 5.3123 & $3.082 \mathrm{e}-008$ & 0.55 \\
\hline
\end{tabular}




\section{International Journal of Science and Research (IJSR) \\ ISSN (Online): 2319-7064 \\ Index Copernicus Value (2013): 6.14 | Impact Factor (2014): 5.611}

Table 1: Performance of Hadamard complementary method

\begin{tabular}{|c|c|c|c|}
\hline $\begin{array}{c}\text { FIBER } \\
\text { LENGTH }\end{array}$ & $\begin{array}{c}\text { MAX } \\
\text { Q FACTOR }\end{array}$ & MIN BER & $\begin{array}{c}\text { DECISION } \\
\text { INSTANT }\end{array}$ \\
\hline $10 \mathrm{KM}$ & 114.114 & 0 & 0.48 \\
\hline $20 \mathrm{KM}$ & 61.5747 & 0 & 0.50 \\
\hline $30 \mathrm{KM}$ & 31.5079 & $3.388 \mathrm{e}-218$ & 0.55 \\
\hline $40 \mathrm{KM}$ & 17.554 & $2.728 \mathrm{e}-069$ & 0.54 \\
\hline
\end{tabular}

Table 2: Performance of Hadamard AND method

\begin{tabular}{|c|c|c|c|}
\hline $\begin{array}{c}\text { FIBER } \\
\text { LENGTH }\end{array}$ & $\begin{array}{c}\text { MAXQ } \\
\text { FACTOR }\end{array}$ & MIN BER & $\begin{array}{c}\text { DECISION } \\
\text { INSTANT }\end{array}$ \\
\hline $10 \mathrm{KM}$ & 6.68 & $1.120 \mathrm{e}-011$ & 0.60 \\
\hline $20 \mathrm{KM}$ & 7.30 & $1.384 \mathrm{e}-013$ & 0.36 \\
\hline $30 \mathrm{KM}$ & 8.03 & $4.081 \mathrm{e}-016$ & 0.35 \\
\hline $40 \mathrm{KM}$ & 7.24 & $2.074 \mathrm{e}-013$ & 0.37 \\
\hline
\end{tabular}

Table 3: Performance of DWC-complementary method

\begin{tabular}{|c|c|c|c|}
\hline $\begin{array}{c}\text { FIBER } \\
\text { LENGTH }\end{array}$ & $\begin{array}{c}\text { MAX Q } \\
\text { FACTOR }\end{array}$ & MIN BER & $\begin{array}{c}\text { DECISION } \\
\text { INSTANT }\end{array}$ \\
\hline $10 \mathrm{KM}$ & 12.39 & $9.625 \mathrm{e}-036$ & 0.49 \\
\hline $20 \mathrm{KM}$ & 11.62 & $1.145 \mathrm{e}-031$ & 0.45 \\
\hline $30 \mathrm{KM}$ & 10.04 & $4.196 \mathrm{e}-024$ & 0.40 \\
\hline $40 \mathrm{KM}$ & 8.1228 & $2.129 \mathrm{e}-016$ & 0.36 \\
\hline
\end{tabular}

Table 4: Performance of DWC-NAND method

\begin{tabular}{|c|c|c|c|}
\hline $\begin{array}{c}\text { FIBER } \\
\text { LENGTH }\end{array}$ & $\begin{array}{c}\text { MAX Q } \\
\text { FACTOR }\end{array}$ & MIN BER & $\begin{array}{c}\text { DECISION } \\
\text { INSTANT }\end{array}$ \\
\hline $10 \mathrm{KM}$ & 62.394 & 0 & 0.51 \\
\hline $20 \mathrm{KM}$ & 44.359 & 0 & 0.53 \\
\hline $30 \mathrm{KM}$ & 27.192 & $3.972 \mathrm{e}-163$ & 0.55 \\
\hline $40 \mathrm{KM}$ & 16.424 & $6.351 \mathrm{e}-061$ & 0.53 \\
\hline
\end{tabular}

Table 5: Performance of DWC- AND method

\begin{tabular}{|c|c|c|c|}
\hline $\begin{array}{c}\text { FIBER } \\
\text { LENGTH }\end{array}$ & $\begin{array}{c}\text { MAX Q } \\
\text { FACTOR }\end{array}$ & MIN BER & $\begin{array}{c}\text { DECISION } \\
\text { INSTANT }\end{array}$ \\
\hline $10 \mathrm{KM}$ & 113.521 & 0 & 0.48 \\
\hline $20 \mathrm{KM}$ & 61.7169 & 0 & 0.50 \\
\hline $30 \mathrm{KM}$ & 31.6586 & $2.884 \mathrm{e}-220$ & 0.55 \\
\hline $40 \mathrm{KM}$ & 17.6503 & $5.035 \mathrm{e}-070$ & 0.54 \\
\hline
\end{tabular}

Table 6: Performance of DWC- XOR method

\begin{tabular}{|c|c|c|c|}
\hline $\begin{array}{c}\text { FIBER } \\
\text { LENGTH }\end{array}$ & $\begin{array}{c}\text { MAX Q } \\
\text { FACTOR }\end{array}$ & MIN BER & $\begin{array}{c}\text { DECISION } \\
\text { INSTANT }\end{array}$ \\
\hline $10 \mathrm{KM}$ & 3.03 & 0 & 0.36 \\
\hline $20 \mathrm{KM}$ & 3.34 & 0 & 0.43 \\
\hline $30 \mathrm{KM}$ & 3.41 & 0 & 0.51 \\
\hline $40 \mathrm{KM}$ & 3.37 & 0 & 0.60 \\
\hline
\end{tabular}

Table 7: Performance of EDWC-complementary method

\begin{tabular}{|c|c|c|c|}
\hline $\begin{array}{c}\text { FIBER } \\
\text { LENGTH }\end{array}$ & $\begin{array}{c}\text { MAX Q } \\
\text { FACTOR }\end{array}$ & $\begin{array}{c}\text { MIN } \\
\text { BER }\end{array}$ & $\begin{array}{c}\text { DECISION } \\
\text { INSTANT }\end{array}$ \\
\hline $10 \mathrm{KM}$ & 2.15 & 0.01 & 0.98 \\
\hline $20 \mathrm{KM}$ & 1.92 & 0.02 & 0.96 \\
\hline $30 \mathrm{KM}$ & 1.75 & 0.03 & 0.94 \\
\hline $40 \mathrm{KM}$ & 1.71 & 0.04 & 0.92 \\
\hline
\end{tabular}

Table 8: Performance of EDWC-NAND method

\begin{tabular}{|c|c|c|c|}
\hline $\begin{array}{c}\text { FIBER } \\
\text { LENGTH }\end{array}$ & $\begin{array}{c}\text { MAX Q } \\
\text { FACTOR }\end{array}$ & MIN BER & $\begin{array}{c}\text { DECISION } \\
\text { INSTANT }\end{array}$ \\
\hline $10 \mathrm{KM}$ & 90.4372 & 0 & 0.48 \\
\hline $20 \mathrm{KM}$ & 53.3056 & 0 & 0.51 \\
\hline $30 \mathrm{KM}$ & 29.2378 & $3.23 \mathrm{e}+008$ & 0.55 \\
\hline $40 \mathrm{KM}$ & 16.7414 & $1.80 \mathrm{e}+008$ & 0.54 \\
\hline
\end{tabular}

Table 9: Performance of EDWC-AND method

\begin{tabular}{|c|c|c|c|}
\hline $\begin{array}{c}\text { FIBER } \\
\text { LENGTH }\end{array}$ & $\begin{array}{c}\text { MAX Q } \\
\text { FACTOR }\end{array}$ & MIN BER & $\begin{array}{c}\text { DECISION } \\
\text { INSTANT }\end{array}$ \\
\hline $10 \mathrm{KM}$ & 88.8456 & 0 & 0.48 \\
\hline $20 \mathrm{KM}$ & 52.3124 & 0 & 0.51 \\
\hline $30 \mathrm{KM}$ & 28.7345 & $7.02 \mathrm{e}-061$ & 0.55 \\
\hline $40 \mathrm{KM}$ & 16.4676 & $3.48 \mathrm{e}-061$ & 0.54 \\
\hline
\end{tabular}

When comparing all models the best ones are EDWC-AND $\&$ EDWC-XOR. They have good Q-factor and supports maximum users with minimum hardware.

\section{Conclusion}

A new AND\& XOR detection technique based on subtraction technique has been proposed. The performance of the hybrid SCM SAC-OCDMA system with the new AND subtraction technique using DW \& EDW code family has been presented. The results of the experimental simulation have proved that the new AND\& XOR subtraction technique provides a better performance than the complementary subtraction technique. The Q-factor for DWC-AND method is 62.39, EDWC-AND is 90.4372 and EDWC-XOR is 88.8456 . We can see that EDWC-AND and EDWC-XOR is best of all, even though some other models proves to be best on behalf of Q-factor; it degrades fastly as per additional users and increasing fiber length. The performance of the system improved significantly because the total power loss is reduced as AND \& XOR subtraction technique requires less number of filters in the decoder.

The EDWC-AND \& EDWC-XOR detection technique implemented in OCDMA system proves to be the most efficient as it can have higher Q-Factor, high SNR, high bandwidth, very wide spectrum and can support maximum number of users.

\section{References}

[1] "Comparative Performance of Hybrid SCM SAC OCDMA System Using Complementary and AND Subtraction Detection Techniques" The International Arab Journal of Information Technology, Vol. 5, No. 1, January 2008.

[2] "Spectral amplitude coding OCDMA systems using enhanced double weight code "Journal of Engineering Science and Technology Vol. 1, No. 2 (2014) 192- 202 (C) School of Engineering, Taylor's University College. 
[3] "Advanced Modulation Techniques in OCDMA System “ Xu Wang*(1, 2), N. Wada(1), T. Miyazaki(1), G. Cincotti (3), and K. Kitayama (4)

[4] "Analysis of the Performance of Optical Code-Division Multiple-Access System (OCDMA), Operating with Gold Codes under Nonlinear Effects "Journal of Electromagnetic Analysis and Applications, 2013, 5, 4957

\section{Author Profile}

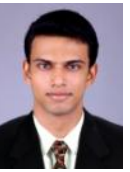

Jeffrey Simon $\mathbf{V}$ is pursuing M-Tech on Communication Engineering at FISAT, Angamali, Mookkanoor, Ernakulam, Kerala, India. Completed B-Tech on Electronics and Communication from Sreenarayana Mangalam Institute of Management and Technology, North Paravur, Ernakulam, Kerala, India. He completed plus two and tenth grade from S. N. Vidya Bhavan, Senior Secondary School, Chentrappinni in the years 2010 and 2008 respectively.

(क) Dhanya .S is working as Assistant Professor at FISAT, Angamali, Mookanoor, Ernakulam, Kerala, India. She completed M-Tech on Communication Engineering at FISAT with $1^{\text {st }}$ Rank in MG University, Angamali, Mookkanoor, Ernakulam, Kerala, India 